\title{
Downregulation of SM22 $\alpha$ protein by hypermethylation of its promoter in colorectal cancer
}

\author{
YABIN LIU ${ }^{1}$, ERQIANG WEI ${ }^{1}$, JIAN ZHAO $^{2}$, DEXIAN KONG $^{3}$ and BINGHUI LI ${ }^{1}$ \\ Departments of ${ }^{1}$ General Surgery, ${ }^{2}$ Obstetrics and Gynaecology and ${ }^{3}$ Endocrinology, \\ The Fourth Affiliated Hospital of Hebei Medical University, Shijiazhuang, Hebei 050011, P.R. China
}

Received July 16, 2017; Accepted February 21, 2018

DOI: $10.3892 / \mathrm{ol} .2018 .8350$

\begin{abstract}
Silencing of tumor suppressor genes by hypermethylation in gene promoter regions is a crucial mechanism in carcinogenesis. Gene methylation may be reversible and evaluated easily, thus providing a promising substrate for the development of biomarkers for the detection and prevention of cancer, including colorectal cancer (CRC). In the present study, the protein expression and methylation status of smooth muscle protein $22 \alpha(\mathrm{SM} 22 \alpha)$ was investigated in 78 cases of $\mathrm{CRC}$ and adjacent normal tissue. The aim of the study was to investigate the function of SM22 $\alpha$ in the pathogenesis of CRC and to identify a candidate biomarker for the early detection of CRC. The methylation status of promoter of SM22 $\alpha$ gene was detected using methylation-specific polymerase chain reaction. The protein expression of SM $22 \alpha$ was evaluated using western blot analysis. The results demonstrated a significant decrease of SM $22 \alpha$ protein expression in $50(68.5 \%)$ cases of CRC compared with that in adjacent normal tissues $(\mathrm{P}<0.001)$. The methylation status of SM22 $\alpha$ promoter in CRC was significantly increased compared with that in adjacent normal tissues $(\mathrm{P}<0.001)$. Additionally, there was a negative correlation between the expression of SM22 $\alpha$ protein and methylation levels of SM22 $\alpha$ gene in CRC $(\mathrm{P}<0.001)$. Kaplan-Meier curves revealed that patients with $\mathrm{CRC}$ with an unmethylated promoter of SM22 $\alpha$ gene exhibited an increased survival time $(34.8 \pm 0.6$ vs. $30.9 \pm 1.3$ months; $\mathrm{P}=0.025$ ) compared with that in patients with a methylated promoter of SM22 $\alpha$ gene. The present study demonstrated that the protein expression of SM22 $\alpha$ is downregulated in CRC tissues by hypermethylation of its promoter, and that the methylation of SM22 $\alpha$ promoter may be used as a biomarker for early detection, prognosis and prediction of CRC.
\end{abstract}

Correspondence to: Professor Binghui Li, Department of General Surgery, The Fourth Affiliated Hospital of Hebei Medical University, 12 Jiankang Road, Shijiazhuang, Hebei 050011, P.R. China

E-mail: 13930126338@163.com

Key words: colorectal cancer, smooth muscle protein $22 \alpha$, methylation, western blot analysis, gene expression

\section{Introduction}

Colorectal cancer (CRC) is a common gastrointestinal malignancy. It is the third most common cancer worldwide and accounts for $>600,000$ mortalities annually $(1,2)$. The 5 -year relative survival rate for patients with CRC is $<65 \%$ (3). Early diagnosis and treatment are crucial to increase the survival rate of patients with CRC. However, there is a lack of highly sensitive and specific biomarkers for detection and prognosis of CRC.

CRC is a complex disease that is caused by genetic and epigenetic alterations $(4,5)$. Epigenetic alterations are stable changes in gene expression, without altering the underlying DNA sequence (6). DNA methylation is a common epigenetic alteration and serves a key function in the regulation of gene activity. Hypermethylation in gene promoter regions may lead to transcriptional silencing (7). Silencing of tumor suppressor genes is a crucial mechanism involved in carcinogenesis (8). Gene methylation may be reversible and may be modified by environmental factors (9). It is reasonable to hypothesize that methylated genes may be attractive candidates for the detection and prevention of cancer. Previous studies suggested several aberrantly methylated tumor suppressor genes to be used as biomarkers for the early detection and prognosis of CRC $(10,11)$. However, their diagnostic sensitivity and specificity remains unsatisfactory.

Smooth muscle protein $22 \alpha$ (SM22 $\alpha$ ), also known as transgelin or TAGLN, is an actin-binding protein that is abundantly expressed in smooth muscle cells in vertebrates (12). Although the biological function of SM22 $\alpha$ remains unclear, it has been suggested to regulate muscle fiber contractility, cell differentiation, cell migration, tissue invasion and tumor suppression (13-16). Accumulating evidence suggests that SM22 $\alpha$ may act as a tumor suppressor. Previous studies reported decreased expression of SM22 $\alpha$ in several types of human cancer, including lung, prostate, renal and breast cancer (17-20). The function of SM22 $\alpha$ was also reported to be associated with increased apoptosis of prostate cancer cells (21). Furthermore, it was demonstrated that SM22 $\alpha$ may suppress the expression of matrix metalloproteinase 9 (MMP-9), which serves an important function in tumor progression (22). A previous study demonstrated that SM22 $\alpha$ expression was significantly decreased in CRC (23). However, the molecular mechanism underlying the downregulation of $\mathrm{SM} 22 \alpha$ in CRC remains to be elucidated. 
In the present study, the methylation status and protein expression of SM22 $\alpha$ is examined in CRC and adjacent normal tissue. To the best of our knowledge, this is the first study to investigate the association between the protein expression and methylation level of SM22 $\alpha$ in CRC tissues and their adjacent normal tissues. The aim of the present study is to investigate the function of SM22 $\alpha$ in the pathogenesis of CRC, and to identify candidate biomarkers for the detection and prognosis of CRC.

\section{Materials and methods}

Tissue extraction. A total of $78 \mathrm{CRC}$ tissues and adjacent normal tissues were obtained from the Department of General Surgery of the Fourth Hospital of Hebei Medical University (Hebei, China) between October 2013 and November 2014. The mean age of the patients was 62 years (range, 42-78 years). A total of 45 cases were male and 33 were female. Postoperative pathological examination confirmed the diagnosis of CRC. No patients received chemotherapy, radiotherapy or immunotherapy prior to surgery. Adjacent normal tissues were collected $\geq 10 \mathrm{~cm}$ away from the edge of the tumor. CRC tissues and corresponding adjacent normal tissues were snap frozen in liquid nitrogen within $30 \mathrm{~min}$ after their removal and stored at $-80^{\circ} \mathrm{C}$. Following surgery, the patients were followed-up every 3 months. Overall survival was defined as the time from the date of surgery to the date of mortality due to CRC. Disease-free survival was defined as the time from the primary surgical treatment to the date of tumor recurrence or the last follow-up. At the time of the last follow-up, $18(23.08 \%)$ had succumbed to disease, $7(8.97 \%)$ were alive with disease and 53 (67.95\%) were alive without disease. The present study was approved by the Ethics Committee of the Fourth Hospital of Hebei Medical University (Hebei, China) and written informed consent was obtained from all individuals.

Western blot analysis. Total protein was extracted from tissues using a lysis buffer containing 1\% NP-40, $150 \mathrm{mM} \mathrm{NaCl}$, $50 \mathrm{mM}$ Tris ( $\mathrm{pH} 7.5), 0.5 \%$ sodium deoxycholate and $1 \mathrm{mM}$ phenylmethanesulfonyl fluoride. Total protein was quantified using the Lowry method. Equal amount of protein $(30 \mu \mathrm{g})$ was separated by SDS-PAGE (10\% gels) and transferred onto polyvinylidene fluoride membranes. The membranes were blocked with 5\% non-fat milk in Tris-buffered saline with Tween-20 (TBST) at room temperature for $2 \mathrm{~h}$, and then incubated with rabbit polyclonal antibodies against SM $22 \alpha$ (dilution, 1:1,000; Abcam, Cambridge, UK) and GAPDH (dilution, 1:800; Santa Cruz Biotechnology, Inc., Dallas, TX, USA) at $4^{\circ} \mathrm{C}$ overnight. Membranes were washed four times with TBST. Following primary incubation, were incubated with Anti-Rabbit IgG (H\&L) (Goat) Antibody IRDye ${ }^{\circledR}$ 800CW conjugated (dilution, 1:20,000; cat. no. 611-131-122; Rockland Immunochemicals, Inc., Gilbertsville, PA, USA) for $1 \mathrm{~h}$ at room temperature. The immunoreactive bands were visualized using an Odyssey infrared imaging system (LI-COR Biosciences, Lincoln, NE, USA). For quantification, the bands were analyzed using ImageQuant software (version 3.0; LI-COR Biosciences), and the signal densities of the SM22 $\alpha$ bands were normalized to those of the
GAPDH bands. SM22 $\alpha$ expression was quantified as a ratio to GAPDH expression (SM22 $\alpha /$ GAPDH ratio). The experiment was repeated three times.

DNA extraction and bisulfite modification. Total DNA was extracted from tissues using the TIANamp Genomic DNA kit (Tiangen Biotech Co., Ltd., Beijing, China). The purity and concentration of the DNA was evaluated using a UV spectrophotometer. DNA (500 ng) was modified by sodium bisulfite using the EZ DNA Methylation-Gold kit (Zymo Research Corp., Irvine, CA, USA), according to the manufacturer's protocol.

Methylation-specific polymerase chain reaction $(P C R)$ $(M S P)$. Methylation-specific PCR primers were designed using MethPrimer software (Sangon Biotech Co., Ltd., Shanghai, China). The primers for methylated SM22 $\alpha$ were as follows: 5'-AATAGTGAAGTAGGAGTAGTCGTA AGTTC-3' (forward) and 5'-AATCTACCGAAACTACCG AAAC-3' (reverse). The primers for unmethylated SM22 $\alpha$ were as follows: 5'-GAATAGTGAAGTAGGAGTAGTTGT AAGTTT-3' (forward) and 5'-CAATCTACCAAAACTACC AAAAC-3' (reverse). The PCR reaction contained Platinum SYBR-Green qPCR SuperMix-UDG (Invitrogen; Thermo Fisher Scientific, Inc., Waltham, MA, USA) (12.5 $\mu \mathrm{l})$, template DNA $(1 \mu \mathrm{l})$, primers (each $0.5 \mu \mathrm{l})$ and diethylpyrocarbonate $\mathrm{H}_{2} \mathrm{O}(10.5 \mu \mathrm{l})$. The thermocycling conditions were as follows: Initial denaturation at $95^{\circ} \mathrm{C}$ for $5 \mathrm{~min}$, followed by 40 cycles at $95^{\circ} \mathrm{C}$ for $30 \mathrm{sec}$, annealing at $64^{\circ} \mathrm{C}$ for $30 \mathrm{sec}$, elongation at $72^{\circ} \mathrm{C}$ for $45 \mathrm{sec}$ and extension at $72^{\circ} \mathrm{C}$ for $10 \mathrm{~min}$. The PCR product for methylated and unmethylated SM22 $\alpha$ was 149 and $151 \mathrm{bp}$, respectively. Amplification products were analyzed by $2 \%$ agarose gel electrophoresis. Peripheral blood DNA that was treated with SssI methyltransferase (New England BioLabs, Inc., Ipswich, MA, USA) was used as a positive control and deionized water was used as a negative control. The gel was visualized under UV illumination.

Statistical analysis. Data were analyzed using SPSS software (version 21.0; IBM Corp., Armonk, NY, USA). Quantitative values of protein expressions in CRC tissues and adjacent normal tissues were analyzed with paired Student's t-test and expressed as mean \pm standard deviation (SD). The methylation rate of SM $22 \alpha$ between CRC tissues and adjacent normal tissues were analyzed using the $\chi^{2}$ test. The Association of the protein expression and methylation status of SM22 $\alpha$ with clinical parameters of patients with CRC was compared using the $\chi^{2}$ test. The log-rank test and Kaplan-Meier survival curve method were used for survival analysis. $\mathrm{P}<0.05$ was considered to indicate a statistically significant difference.

\section{Results}

Protein expression and methylation level of SM22 $\alpha$ in CRC tissues and adjacent normal tissues. The relative protein expression of SM22 $\alpha$ was analyzed in 78 pairs of CRC tissues and their adjacent normal tissues using western blot analysis (Fig. 1). The results demonstrated a significantly decreased expression of SM22 $\alpha$ in 50 (68.5\%) cases of CRC. Additionally, 

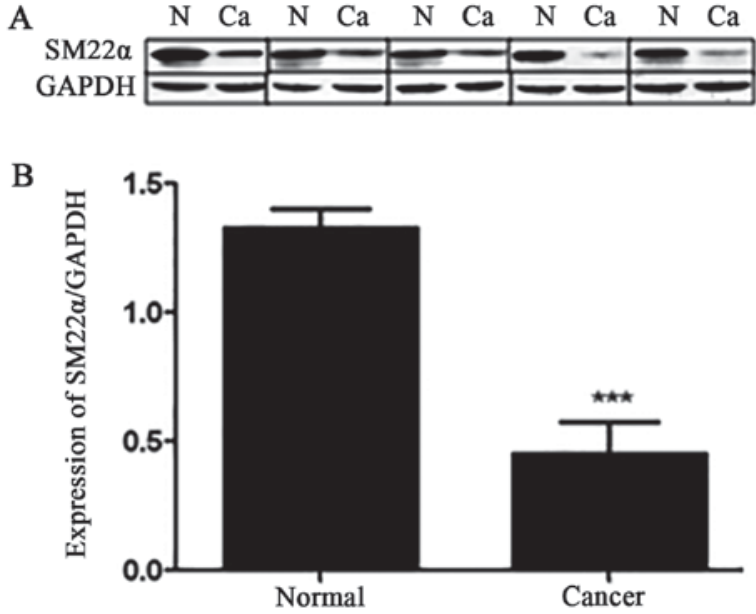

Figure 1. Expression of SM22 $\alpha$ in colorectal cancer tissues and adjacent normal tissues. (A) Representative images and (B) quantification from western blot analysis of SM22 $\alpha$ expression in 78 colorectal cancer tissues and their adjacent normal tissues. ${ }^{* * *} \mathrm{P}<0.001$ vs. normal tissues. $\mathrm{N}$, adjacent normal tissues; $\mathrm{Ca}$, colorectal cancer tissues; SM22 $\alpha$, smooth muscle protein $22 \alpha$.

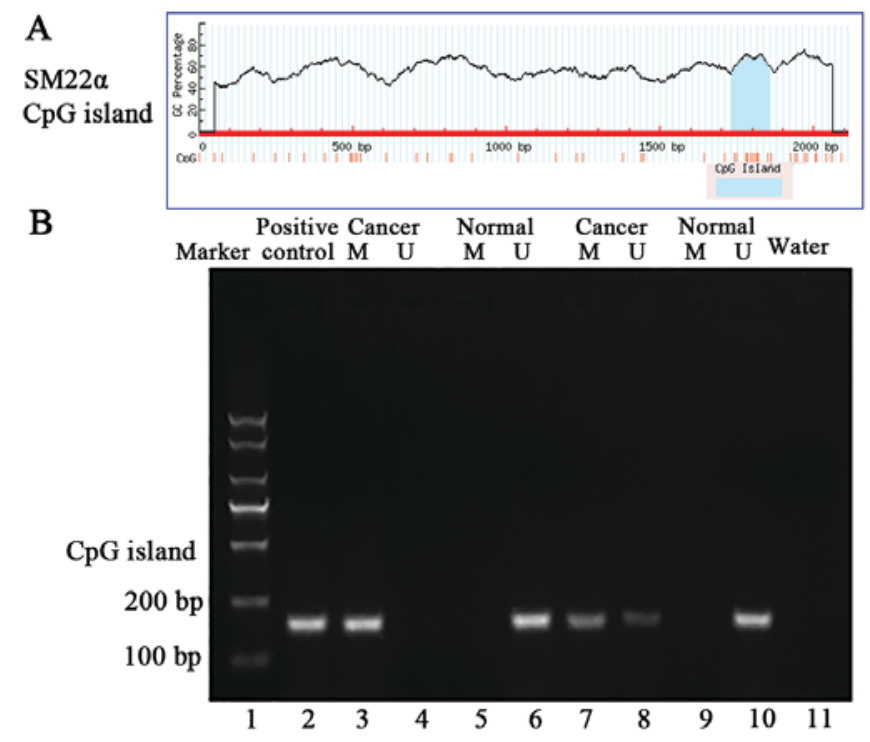

Figure 2. MSP of the CpG island of SM22 $\alpha$ in colorectal cancer and adjacent normal tissues. (A) UCSC genome browser view of SM22 $\alpha$ and distribution of CpG sites. (B) MSP products for SM22 $\alpha$ promoter regions on an agarose gel. Lane 1, DNA marker; lane 2, methylation-positive control; lane 3-6, a representative case of colorectal cancer; lane 7-10, a representative case of colorectal cancer; lane 11, negative control. M, methylated; U, unmethylated SM22 $\alpha$, smooth muscle protein $22 \alpha$; MSP, methylation-specific polymerase chain reaction.

$28(31.5 \%)$ cases of CRC exhibited an unchanged or upregulated expression of SM22 $\alpha$. Fig. 1A shows representative western blot analysis of the expression of SM22 $\alpha$ from five cases of CRC. SM22 $\alpha$ was decreased by 2 -fold in CRC tissues compared with that in adjacent normal tissues (mean $\pm \mathrm{SD}$, $0.7280 \pm 0.1412$ vs. $1.4458 \pm 0.3433$; paired Student's t-test, $\mathrm{P}<0.001$; Fig. 1B).

To investigate the molecular mechanisms of SM22 $\alpha$ gene regulation in $\mathrm{CRC}$, DNA methylation levels within promoter $\mathrm{CpG}$ islands, were evaluated. The results demonstrated that methylation of SM22 $\alpha \mathrm{CpG}$ island in CRC tissues and adjacent normal tissues was $59.0 \%$ (43/78) and $21.9 \%$ (19/78), respectively. The difference was statistically significant $\left(\chi^{2}=15.418\right.$, $\mathrm{P}<0.001$; Fig. 2) (Data not shown). Fig. 2B shows data from two cases of CRC.

Association of the protein expression and methylation status of SM22 $\alpha$ with clinical parameters of patients with CRC. Statistical analysis of SM22 $\alpha$ protein expression, SM $22 \alpha$ gene methylation and clinical variables was performed using the $\chi^{2}$ test. The expression of SM $22 \alpha$ protein and methylation levels of SM22 $\alpha$ gene were not associated with age, sex, tumor differentiation, tumor stage, lymph node metastasis, tumor infiltration depth or tumor location in patients with colorectal cancer (Table I).

Association of the protein expression and methylation status of SM22 $\alpha$ in CRC tissues. Patients with CRC were divided into SM22 $\alpha$ high- and low-expression groups on the basis of western blot analysis. The association between the protein expression and the methylation status of SM22 $\alpha$ was determined in CRC tissues. SM22 $\alpha$ was methylated in 40 of 43 cases of CRC with low protein expression of SM22 $\alpha$. SM $22 \alpha$ was unmethylated in 25 of 35 cases of CRC with increased protein expression of SM22 $\alpha$. Therefore, there was a negative association between the protein expression and methylation levels of SM22 $\alpha$ in CRC ( $\mathrm{P}<0.001 ;$ Table II).

Methylation status of SM22 $\alpha$ and survival time in patients with CRC. Kaplan-Meier survival curves revealed that patients with CRC with unmethylated promoter of SM22 $\alpha$ presented a significantly longer overall survival time (34.8 \pm 0.6 months) compared with that in patients with a methylated SM22 $\alpha$ promoter status $(30.9 \pm 1.3$ months; log-rank test, $\mathrm{P}=0.025$; Fig. 3A). Additionally, patients with CRC with unmethylated promoter of SM22 $\alpha$ exhibited a longer disease-free survival time (32.5 \pm 1.3 months) compared with that in patients with a methylated SM22 $\alpha$ promoter status $(26.0 \pm 1.9$ months; log-rank test, $\mathrm{P}=0.027$; Fig. 3B).

\section{Discussion}

SM22 $\alpha$ is an early differentiation marker of smooth muscle cells, which is expressed in fibroblasts and epithelial cells $(13,14)$. SM22 $\alpha$ serves an important function in stabilizing the cellular structure and maintaining the differentiated phenotype of smooth muscle cells via association with actin $(24,25)$. Previous studies have demonstrated that SM $22 \alpha$ may be involved in the development and progression of malignant tumors. Decreased expression of SM22 $\alpha$ has been reported in lung, prostate, renal and breast cancer (17-20). Zhang et al (21) reported that SM22 $\alpha$ may induce apoptosis via interacting with p53 in prostate cancer cells. Nair et al (22) demonstrated that $\mathrm{SM} 22 \alpha$ repressed the expression of MMP-9 via reducing the transactivation of activating protein 1-dependent and compromising the activation of extracellular signal-regulated kinase. Li et al (26) demonstrated that SM22 $\alpha$ may decrease proliferation and invasion, and increase apoptosis in colorectal carcinoma cells. Xu et al (27) reported that SM22 $\alpha$ may prevent the metastasis of CRC. These 
Table I. Association between protein expression and methylation level of SM22 $\alpha$ and clinicopathological characteristics.

\begin{tabular}{|c|c|c|c|c|c|}
\hline \multirow[b]{2}{*}{ Clinical parameters } & \multirow[b]{2}{*}{ Number (n) } & \multicolumn{2}{|c|}{$\begin{array}{c}\text { Decrease of SM22 } \alpha \\
\text { protein expression }\end{array}$} & \multicolumn{2}{|c|}{ SM22 $\alpha$ methylation } \\
\hline & & Cases (n) & $\mathrm{P}$-value ${ }^{\mathrm{a}}$ & $\mathrm{M}(\mathrm{n})$ & P-value ${ }^{a}$ \\
\hline \multicolumn{6}{|l|}{ Age (years) } \\
\hline$<60$ & 31 & 22 & 0.305 & 19 & 0.374 \\
\hline$\geq 60$ & 47 & 28 & & 24 & \\
\hline \multicolumn{6}{|l|}{ Sex } \\
\hline Male & 45 & 26 & 0.174 & 23 & 0.405 \\
\hline Female & 33 & 24 & & 20 & \\
\hline \multicolumn{6}{|l|}{ Differentiation } \\
\hline Level I-II & 62 & 41 & 0.463 & 35 & 0.644 \\
\hline Level III & 16 & 9 & & 8 & \\
\hline \multicolumn{6}{|l|}{ TNM stage } \\
\hline $\mathrm{I}-\mathrm{II}$ & 49 & 29 & 0.239 & 25 & 0.343 \\
\hline III & 29 & 21 & & 18 & \\
\hline \multicolumn{6}{|l|}{ Lymphatic metastasis } \\
\hline No & 51 & 30 & 0.182 & 28 & 0.956 \\
\hline Yes & 27 & 20 & & 15 & \\
\hline \multicolumn{6}{|l|}{ Infiltration depth } \\
\hline $\mathrm{T} 1-\mathrm{T} 2$ & 21 & 13 & 0.806 & 9 & 0.186 \\
\hline T3-T4 & 57 & 37 & & 34 & \\
\hline \multicolumn{6}{|l|}{ Tumor location } \\
\hline Colon & 29 & 19 & 0.841 & 16 & 0.995 \\
\hline Rectal & 49 & 31 & & 27 & \\
\hline
\end{tabular}

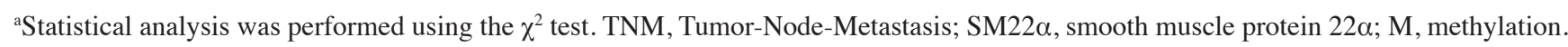

Table II. Association between protein expression and methylation level of SM22 $\alpha$ in colorectal cancer tissues.

\begin{tabular}{lcccc}
\hline & \multicolumn{2}{c}{ SM22 $\alpha$ protein expression } & \\
\cline { 2 - 4 } $\begin{array}{l}\text { SM22 } \alpha \text { promoter } \\
\text { methylation }\end{array}$ & High $^{\mathrm{a}}$ & Low $^{\mathrm{b}}$ & $\chi^{2}$ & P-value \\
\hline Methylated & 3 & 40 & & \\
Unmethylated & 25 & 10 & 34.832 & $<0.001$ \\
\hline
\end{tabular}

${ }^{\text {aSM}} 22 \alpha$ protein expression was increased in colorectal cancer tissues compared with that in adjacent normal tissues. ${ }^{\mathrm{b}} \mathrm{S} M 22 \alpha$ protein expression was decreased in colorectal cancer tissues compared with that in adjacent normal tissues. SM22 $\alpha$, smooth muscle protein $22 \alpha$.

findings indicate that SM22 $\alpha$ may act as a tumor suppressor. However, the pathological function of SM22 $\alpha$ may depend on the type of cancer. For example, upregulation of SM22 $\alpha$ has been reported in gastric cancer and esophageal squamous cell carcinoma $(28,29)$. Therefore, further research on the expression and function of SM22 $\alpha$ in various tumor types is required.

The results of the present study demonstrated a decreased expression of SM22 $\alpha$ in CRC tissues compared with that in adjacent normal tissues. However, the protein level of SM22 $\alpha$ was not associated with age, sex, tumor differentiation, tumor stage, lymph node metastasis, tumor infiltration depth or tumor location. This implies that SM22 $\alpha$ may be used as a biomarker of colorectal carcinogenesis and may serve as a tumor suppressor. These results are consistent with those of previous studies $(23,30,31)$. However, Zhou et al (32) and Lin et al (33) reported that elevated levels of SM22 $\alpha$ increased invasiveness and lymph node metastasis in CRC. The discrepancy between these results and the present findings may arise from the limited sample size.

The expression of SM22 $\alpha$ is regulated at the transcriptional level (34). Yamamura et al (35) demonstrated that the transcriptional activity of SM22 $\alpha$ was regulated by the methylation of the promoter region in smooth muscle cells. Zhao et al (30) revealed that treatment with 5-aza-2-deoxycytidine may restore the mRNA and protein levels of SM22 $\alpha$ in the human intestinal epithelial cell line HT29. However, the association between the protein expression and methylation status of SM22 $\alpha$ in CRC tissues and adjacent normal tissues remains unclear. The results of the present study revealed an increased methylation level of SM22 $\alpha$ in CRC tissues compared with that in adjacent normal tissues. Additionally, there was a negative association between the methylation level and protein expression of 

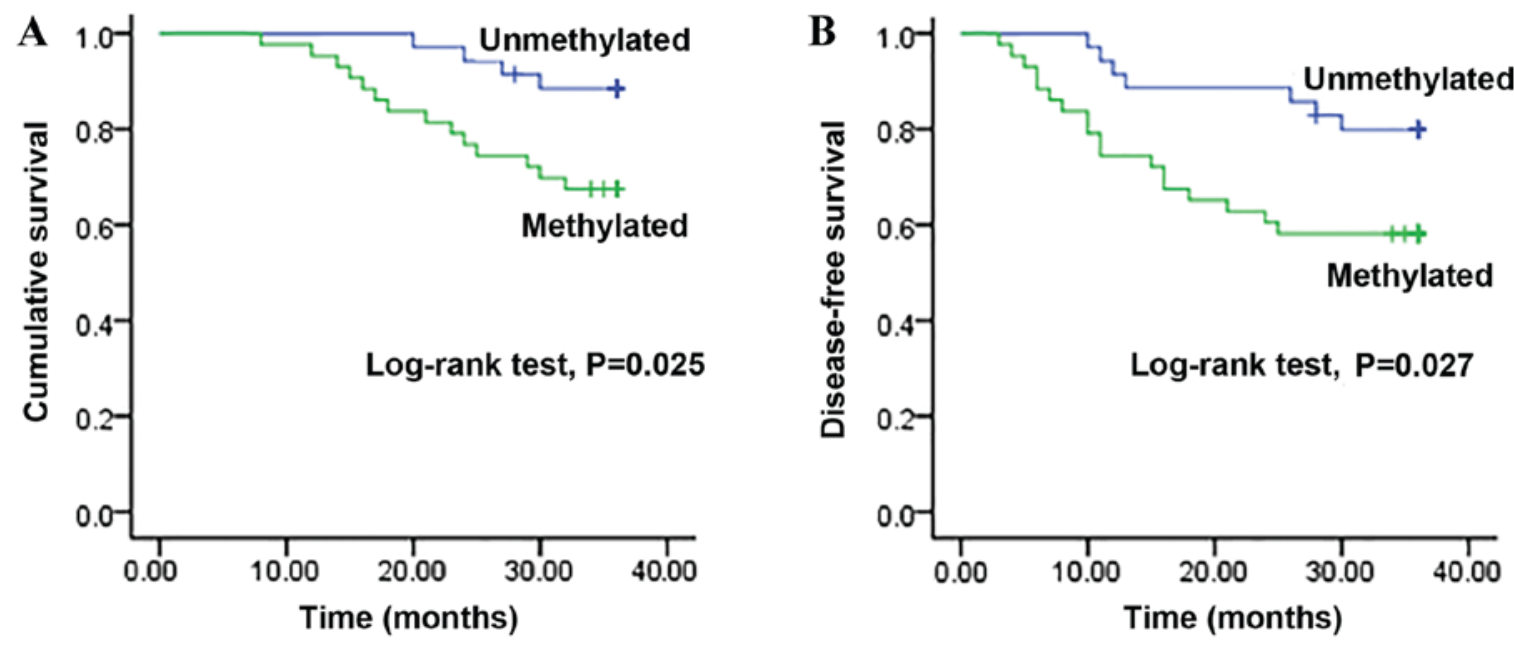

Figure 3. Kaplan-Meier survival analysis for patients with colorectal cancer with methylated and unmethylated levels of SM22 $\alpha$. (A) Overall survival and (B) disease-free survival of patients with colorectal cancer with unmethylated or methylated promoter of SM22 $\alpha$. SM22 $\alpha$, smooth muscle protein $22 \alpha$.

SM22 $\alpha$ in CRC tissues. The results indicated that hypermethylation of SM22 $\alpha$ may be important in the regulation of SM22 $\alpha$ transcription.

DNA hypermethylation results in gene silencing, and silencing of tumor suppressor genes is involved in carcinogenesis $(8,36)$. Aberrantly methylated tumor suppressor genes may act as potential biomarkers for the early detection of tumors. The results of the present study demonstrated that the methylation level of SM22 $\alpha$ promoter was increased in CRC tissues compared with that in adjacent normal tissues. However, methylation of SM22 $\alpha$ promoter was not associated with age, sex, tumor differentiation, tumor stage, lymph node metastasis, tumor infiltration depth or tumor location. These results suggested that hypermethylation of SM22 $\alpha$ gene may occur at early stages of colorectal carcinogenesis and therefore may be a biomarker for the early diagnosis of CRC. Additionally, patients with an unmethylated promoter of SM22 $\alpha$ gene exhibited a longer survival time compared with that in patients with methylated promoter of SM22 $\alpha$ gene, indicating that the methylation status of SM22 $\alpha$ promoter region may be associated with the prognosis of patients with CRC.

The present study has several limitations. First, the sample size was small and further large-scale studies are required to confirm the results of the present study. Secondly, methylation status and protein expression of SM22 $\alpha$ was not evaluated in healthy individuals. Finally, further studies are required to evaluate the methylation levels of SM22 $\alpha$ in the plasma or serum in patients with CRC.

In conclusion, the results of the present study demonstrated that the protein expression of SM22 $\alpha$ was significantly decreased in patients with CRC. Additionally, the methylation level in the SM22 $\alpha$ gene promoter region was increased in CRC tissues compared with that in adjacent normal tissues. There was a negative association between the protein expression and methylation levels of SM22 $\alpha$. Kaplan-Meier survival analysis revealed that patients with CRC with an unmethylated promoter of SM22 $\alpha$ gene exhibited an improved survival time compared with that in patients with methylated promoter of SM $22 \alpha$ gene. Therefore, the methylation level of SM22 $\alpha$ promoter may be a useful biomarker for early detection, prognosis and prediction of CRC.

\section{Acknowledgements}

The authors would like to acknowledge the doctors in the Department of General Surgery of the Fourth Hospital of Hebei Medical University, China, for their assistance in recruiting study participants.

\section{Funding}

The present study was supported by the National Natural Science Foundation of China (grant no. 81372150) and the Health and Family Planning Commission of Hebei Province (Hebei, China; grant no. 20170732).

\section{Authors' contributions}

BL, YL and EW designed the study and applied for approval from the Research Ethics Board. YL and DK recruited the patients and collected the data. BL, YL and JZ analyzed the data and prepared draft figures and tables. YL prepared the manuscript draft with important intellectual input from BL, EW and JZ.

\section{Ethics approval and consent to participate}

The present study was approved by the Ethics Committee of the Fourth Hospital of Hebei Medical University (Hebei, China) and written informed consent was obtained from all individuals.

\section{Consent for publication}

All study participants provided written informed consent for the data to be published.

\section{Competing interests}

The authors declare that they have no competing interests. 


\section{References}

1. Ferlay J, Soerjomataram I, Dikshit R, Eser S, Mathers C, Rebelo M, Parkin DM, Forman D and Bray F: Cancer incidence and mortality worldwide: Sources, methods and major patterns in GLOBOCAN 2012. Int J Cancer 136: E359-E386, 2015.

2. Shaukat A, Mongin SJ, Geisser MS, Lederle FA, Bond JH, Mandel JS and Church TR: Long-term mortality after screening for colorectal cancer. N Engl J Med 369: 1106-1114, 2013.

3. Siegel R, Desantis C and Jemal A: Colorectal cancer statistics, 2014. CA Cancer J Clin 64: 104-117, 2014.

4. Migliore L, Igheli F, Spisni R and Coppede F: Genetics, Cytogenetics, and epigenetics of colorectal cancer. J Biomed Biotech 2011: 792362, 2011.

5. Grady WM and Ulrich CM: DNA alkylation and DNA methylation: Cooperating mechanisms driving the formation of colorectal adenomas and adenocarcinomas? Gut 56: 318-320, 2007.

6. Inbar-Feigenberg M, Choufani S, Butcher DT, Roifman M and Weksberg R: Basic concepts of epigenetics. Fertil Steril 99: 607-615, 2013.

7. Esteller M: Epigenetic gene silencing in cancer: The DNA hypermethylome. Hum Mol Genet 16 Spec No 1: R50-R59, 2007.

8. Ghavifekr Fakhr M, Farshdousti Hagh M, Shanehbandi D and Baradaran B: DNA methylation pattern as important epigenetic criterion in cancer. Genet Res Int 2013: 317569, 2013.

9. Jaenisch R and Bird A: Epigenetic regulation of gene expression: How the genome integrates intrinsic and environmental signals. Nat Genet 33 (Suppl): S245-S254, 2003.

10. Carmona FJ, Azuara D, Berenguer-Llergo A, Fernández AF, Biondo S, de Oca J, Rodriguez-Moranta F, Salazar R, Villanueva A, Fraga MF, et al: DNA methylation biomarkers for noninvasive diagnosis of colorectal cancer. Cancer Prev Res (Phila) 6: 656-665, 2013.

11. Ahn JB, Chung WB, Maeda O, Shin SJ, Kim HS, Chung HC, Kim NK and Issa JP: DNA methylation predicts recurrence from resected stage III proximal colon cancer. Cancer 117: 1847-1854, 2011.

12. Zhang JC, Kim S, Helmke BP, Yu WW, Du KL, Lu MM, Strobeck M, Yu Q and Parmacek MS: Analysis of SM22alpha-deficient mice reveals unanticipated insights into smooth muscle cell differentiation and function. Mol Cell Biol 21: 1336-1344, 2001

13. Assinder SJ, Stanton JA and Prasad PD: Transgelin: An actin-binding protein and tumour suppressor. Int $\mathrm{J}$ Biochem Cell Biol 41: 482-486, 2009.

14. Lawson D, Harrison M and Shapland C: Fibroblast transgelin and smooth muscle SM22alpha are the same protein, the expression of which is down-regulated in many cell lines. Cell Motil Cytoskeleton 38: 250-257, 1997.

15. Shields JM, Rogers-Graham K and Der CJ: Loss of transgelin in breast and colon tumors and in RIE-1 cells by Ras deregulation of gene expression through Raf-independent pathways. J Biol Chem 277: 9790-9799, 2002.

16. Albiges-Rizo C, Destaing O, Fourcade B, Planus E and Block MR: Actin machinery and mechanosensitivity in invadopodia, podosomes and focal adhesions. J Cell Sci 122: 3037-3049, 2009.

17. Li LS, Kim H, Rhee H, Kim SH, Shin DH, Chung KY, Park KS, Paik YK, Chang J and Kim H: Proteomic analysis distinguishes basaloid carcinoma as a distinct subtype of nonsmall cell lung carcinoma. Proteomics 4: 3394-3400, 2004.

18. Prasad PD, Stanton JA and Assinder SJ: Expression of the actin-associated protein transgelin (SM22) is decreased in prostate cancer. Cell Tissue Res 339: 337-347, 2010.

19. Klade CS, Voss T, Krystek E, Ahorn H, Zatloukal K, Pummer K and Adolf GR: Identification of tumor antigens in renal cell carcinoma by serological proteome analysis. Proteomics 1: 890-898, 2001

20. Sayar N, Karahan G, Konu O, Bozkurt B, Bozdogan O and Yulug IG: Transgelin gene is frequently downregulated by promoter DNA hypermethylation in breast cancer. Clin Epigenetics 7: 104, 2015.
21. Zhang ZW, Yang ZM, Zheng YC and Chen ZD: Transgelin induces apoptosis of human prostate LNCaP cells through its interaction with p53. Asian J Androl 12: 186-195, 2010.

22. Nair RR, Solway J and Boyd DD: Expression cloning identifies transgelin (SM22) as a novel repressor of 92-kDa type IV collagenase (MMP-9) expression. J Biol Chem 281: 26424-26436, 2006.

23. Xie XL, Liu YB, Liu YP, Du BL, Li Y,Han M and Li BH: Reduced expression of SM22 is correlated with low autophagy activity in human colorectal cancer. Pathol Res Pract 209: 237-243, 2013.

24. Gimona M, Kaverina I, Resch GP, Vignal E and Burgstaller G: Calponin repeats regulate actin filament stability and formation of podosomes in smooth muscle cells. Mol Biol Cell 14: 2482-2491, 2003.

25. Han M, Dong LH, Zheng B, Shi JH, Wen JK and Cheng Y: Smooth muscle 22 alpha maintains the differentiated phenotype of vascular smooth muscle cells by inducing filamentous actin bundling. Life Sci 84: 394-401, 2009.

26. Li Q, Shi R, Wang Y and Niu X: TAGLN suppresses proliferation and invasion, and induces apoptosis of colorectal carcinoma cells. Tumour Biol 34: 505-513, 2013.

27. Xu L, Gao Y, Chen Y, Xiao Y, He Q, Qiu H and Ge W: Quantitative proteomics reveals that distant recurrence-associated protein R-Ras and Transgelin predict post-surgical survival in patients with Stage III colorectal cancer. Oncotarget 7: 43868-43893, 2016.

28. Yu B, Chen X, Li J, Qu Y, Su L, Peng Y, Huang J, Yan J, Yu Y, $\mathrm{Gu} \mathrm{Q}$, et al: Stromal fibroblasts in the microenvironment of gastric carcinomas promote tumor metastasis via upregulating TAGLN expression. BMC Cell Biol 14: 17, 2013.

29. Chen JY, Xu L, Fang WM, Han JY, Wang K and Zhu KS: Identification of PA2 $8 \beta$ as a potential novel biomarker in human esophageal squamous cell carcinoma. Tumour Biol 39: 1010428317719780, 2017

30. Zhao L, Wang H, Deng YJ, Wang S, Liu C, Jin H and Ding YQ: Transgelin as a suppressor is associated with poor prognosis in colorectal carcinoma patients. Mod Pathol 22: 786-796, 2009.

31. Yeo M, Park HJ, Kim DK, Kim YB, Cheong JY, Lee KJ and Cho SW: Loss of SM22 is a characteristic signature of colon carcinogenesis and its restoration suppresses colon tumorigenicity in vivo and in vitro. Cancer 116: 2581-2589, 2010.

32. Zhou HM, Fang YY, Weinberger PM, Ding LL, Cowell JK, Hudson FZ, Ren M, Lee JR, Chen QK, Su H, et al: Transgelin increases metastatic potential of colorectal cancer cells in vivo and alters expression of genes involved in cell Motility. BMC Cancer 16: 55, 2016.

33. Lin Y, Buckhaults PJ, Lee JR, Xiong H, Farrell C, Podolsky RH, Schade RR and Dynan WS: Association of the actin-binding protein transgelin with lymph node metastasis in human colorectal cancer. Neoplasia 11: 864-873, 2009.

34. Prinjha RK, Shapland CE, Hsuan JJ, Totty NF, Mason IJ and Lawson D: Cloning and sequencing of cDNAs encoding the actin cross-linking protein transgelin defines a new family of actin-associated proteins. Cell Motil Cytoskeleton 28: 243-255, 1994.

35. Yamamura H, Masuda H, Ikeda W, Tokuyama T, Takagi M, Shibata N, Tatsuta M and Takahashi K: Structure and expression of the human SM22alpha gene, assignment of the gene to chromosome 11, and repression of the promoter activity by cytosine DNA methylation. J Biochem 122: 157-167, 1997.

36. Mohn F, Weber M, Rebhan M, Roloff TC, Richter J, Stadler MB, Bibel M and Schübeler D: Lineage-specific polycomb targets and de novo DNA methylation define restriction and potential of neuronal progenitors. Mol Cell 30: 755-766, 2008.

This work is licensed under a Creative Commons Attribution-NonCommercial-NoDerivatives 4.0 International (CC BY-NC-ND 4.0) License. 